\title{
Observational multicenter study to evaluate the prevalence and prognosis of subclinical atheromatosis in a Spanish chronic kidney disease cohort: baseline data from the NEFRONA study
}

David Arroyo ${ }^{1,2^{*}}$, Angels Betriu ${ }^{1,2,5}$, Montserrat Martinez-Alonso ${ }^{3}$, Teresa Vidal ${ }^{2}$, Jose Manuel Valdivielso ${ }^{4,5}$, Elvira Fernández ${ }^{1,2,4,5}$ and on behalf of the investigators from the NEFRONA study

\begin{abstract}
Background: Cardiovascular events (CVE) are more prevalent in chronic kidney disease (CKD) than in general population, being the main cause of morbimortality. Specific risk factors related to CKD have been suggested, because traditional factors do not fully explain this increase in cardiovascular disease rates. However, the role of atheromatosis, its pathogenesis and evolution are still unclear. The potential use of diagnostic tests to detect subclinical atheromatosis has to be determined.

Methods: NEFRONA is a prospective multicenter cohort study. 2445 CKD subjects were enrolled from 81 Spanish hospitals and dialysis clinics, from 2010 to 2012. Eligibility criteria included: 18 to 74 years old, CKD stage 3 or higher, and no previous CVE. 559 non-CKD controls were also recruited. Demographical, clinical and analytical data were collected. Carotid and femoral ultrasounds were performed by a single trained team to measure carotid intima-media thickness (CIMT) and detect atheromatous plaques. Ankle-brachial index (ABI) was measured.

Results: Differences in age, sex and prevalence and control of cardiovascular risk factors were found between controls and CKD patients. These differences are similar to those described in epidemiological studies.

No difference was found regarding CIMT between controls and CKD (when subjects with plaques in common carotid arteries were omitted); earlier CKD stages had higher values. CKD patients had a higher rate of atheromatous plaques, with no difference between stages in the unadjusted analysis. A group of patients had plaques in femoral arteries but were plaque-free in carotid arteries, and would have gone underdiagnosed without the femoral study. The percentage of pathologic $\mathrm{ABI}$ was higher in $\mathrm{CKD}$, with higher prevalence in more advanced stages, and a higher rate of $\mathrm{ABI}>1.4$ than $<0.9$, suggesting more vascular calcification.
\end{abstract}

Conclusions: NEFRONA is the first large study describing the actual prevalence of subclinical atheromatosis across different CKD stages. There is a very high rate of atheromatous plaques and pathologic ABI in CKD. Prospective data will add important information to the pathogenesis and evolution of atheromatosis in CKD, compared to non-CKD subjects.

Keywords: Chronic kidney disease, Cardiovascular disease, Atheromatosis, Vascular calcification, Intima-media thickness, Ankle-brachial index

\footnotetext{
* Correspondence: dvdrry@gmail.com

${ }^{1}$ Nephrology Department, Hospital Universitari Arnau de Vilanova, Avda. Rovira Roure 80, 25198 Lleida, Spain

${ }^{2}$ Unit for Detection and Treatment of Atherotrombotic Disease (UDETMA),

Nephrology Department, Hospital Universitari Arnau de Vilanova, Avda.

Rovira Roure 80, 25198 Lleida, Spain

Full list of author information is available at the end of the article
} 


\section{Background}

Chronic kidney disease (CKD) is a growing health problem, with increasing morbidity, mortality and monetary costs [1]. Despite the improvement in the treatment of its complications, patients with CKD in any stage continue to have a higher rate of cardiovascular events than subjects with normal renal function. In fact, cardiovascular disease (CVD) continues to be the first mortality cause in this population, and in many recent guidelines it has been stated as a cardiovascular risk factor itself, as severe as diabetes [2].

Important advances have been made in the knowledge of both general and specific cardiovascular risk factors in CKD. However, neither traditional risk factors or risk score charts for general population nor emerging risk biomarkers appear to be good enough predictors in this population [3-6]. It has been suggested that there is a different pathogenesis for CVD in advanced CKD, since most cardiovascular deaths appear to be from sudden deaths. These events have been related to possible arrhythmias or heart failure, related to heart remodelling and microischemia of the myocardium [7-9]. Besides, the effects of reverse epidemiology of many traditional risk factors and the appearance of different mechanisms are involved [10-12].

The presence of accelerated atheromatosis in CKD could also play a role in the higher cardiovascular mortality, in a process that has been termed accelerated vascular aging. However, there is still much to clarify regarding the process of atheromatosis in this group of patients, and the precise contribution of various risk factors. Many serum biomarkers are altered in CKD patients, and their prognostic value is currently under study $[13,14]$, but new tools for adequately assessing asymptomatic atheromatosis are required [15]. The application of diagnostic tests in CKD (i.e. vascular ultrasound or ankle-brachial index) to detect subclinical atheromatosis and adequately stratify cardiovascular risk has not yet been specifically addressed, although there are some initial promising data $[16,17]$.

The NEFRONA project is an observational multicenter prospective study designed to evaluate the prevalence and evolution of subclinical atheromatosis in CKD patients, as well as the contribution of vascular imaging for a more precise cardiovascular risk assessment $[18,19]$. Baseline data of this study are presented in this article.

\section{Methods}

\section{Study design and participants}

NEFRONA is a prospective multicenter cohort study, in which 2445 CKD subjects were enrolled in 81 Spanish hospitals and dialysis clinics, from October 2010 to June 2012. Patients between 18 and 74 years of age were eligible if they had CKD stage 3 or higher as defined by current guidelines (glomerular filtration rate lower than $60 \mathrm{~mL} / \mathrm{min} / 1.73 \mathrm{~m}^{2}$ estimated using the 4-variable Modification of Diet in Renal Disease (MDRD) equation) [20]. Besides, 559 controls with an MDRD over $60 \mathrm{~mL} /$ $\min / 1.73 \mathrm{~m}^{2}$ were recruited from Primary Care centers. Exclusion criteria for both groups included: active infections, pregnancy, life expectancy lower than 12 months, and history of cardiovascular events, carotid artery surgery or any organ transplantation.

The sample size was calculated based on the incidence of cardiovascular events described in the CKD population and depending on the stage of kidney disease [21]. The minimum sample required is based on the number of cases studied to obtain a minimum number of events (assumed to be homogeneously distributed throughout the follow-up period) to adjust the results of the multivariate analysis for 15 variables. We fixed type I and II errors to $5 \%$ (bilateral) and 10\%, respectively. It was assumed a $25 \%$ loss of follow-up, and that both events and losses of follow-up will be proportionally distributed over the study period. Consequently, it was planned to include a total of 2661 patients (1325 stage 3 CKD, 713 stage 4 and 5 CKD, and 623 in dialysis). Furthermore, 843 subjects without renal disease were planned to be included to detect significant differences in the presence of plaques among patients for each stage of kidney disease and subjects without kidney disease (estimated from data provided by the Hospital Arnau de Vilanova, Lleida).

Patients were provided with and signed an informed consent. The local Ethics Committee of the Hospital Arnau de Vilanova approved the protocol.

\section{Clinical and laboratory data}

Recruiting investigators completed a questionnaire with the patients' clinical data, including family history of early cardiovascular disease, cardiovascular risk factors (such as smoking, diabetes, hypertension or dyslipidemia) and current medications. Anthropometrical data and vitals were obtained using standardized methods, as described in the study design [18]. Intact parathyroid hormone, 25hydroxi-vitamin D and 1,25-hydroxi-vitamin D were all measured in a centralized laboratory.

Biochemical parameters were obtained from a routine fasting blood test taken no more than three months apart from the vascular explorations. In hemodialysis patients, samples were obtained before the second dialysis session of the week.

\section{Atherosclerosis assessment}

Detailed and technical information on the methods to evaluate subclinical atherosclerosis has been previously published [18]. All studies were performed with a standardized protocol by three experienced itinerant teams including a nurse and a radiology technician. These teams 
also recorded anthropometrical parameters and collected blood samples to be stored in the REDinRen (Spanish Renal Research Network) centralized biobank for future biomarker studies.

Participants underwent a carotid and femoral ultrasound to measure carotid intima-media thickness (cIMT) and to evaluate the presence and characteristics of atheromatous plaques, defined as a cIMT lumen protrusion $\geq 1.5 \mathrm{~mm}$, as recommended by the American Society of Echocardiography [22]. cIMT was recorded as the mean value between right and left common carotid intima-media thicknesses. There is no current consensus about the way to measure cIMT in patients with atheromatous plaques in common carotid arteries. We propose to use a right-truncated value of $1.5 \mathrm{~mm}$ in the presence of plaques in the corresponding artery and then computing CIMT as the mean value between right and left common-carotid arteries values (equivalent to the median of both values). Plaque presence in other carotid territories was not evaluated for cIMT measurement.

Plaque presence was evaluated in left and right sides, and in various territories (internal and common carotid arteries and carotid bulbs, and common and superficial femoral arteries).

Ankle-brachial index was measured using a protocolized method, and the modified ABI was recorded. This is the lowest value of the four available, and it was preferred because it is the measure with a higher sensitivity for cardiovascular risk assessment [23,24]. A pathologic ABI is defined as a value $<0.9$, diagnostic of a limb ischemia, or $>1.4$, diagnostic of arterial incompressibility and stiffness, usually ascribed to vascular wall calcification.

An atherosclerosis score (AS) was originally designed and described in the study rationale article [18], according to these measures: AS0 (no atheromatosis), ABI $>0.9$ and $\mathrm{CIMT}<90^{\text {th }}$ percentile of reference values; AS1 (mild), ABI between $0.7-0.9$ or CIMT $\geq 90^{\text {th }}$ percentile of reference values; AS2 (moderate), carotid plaque with stenosis $<50$ $70 \%$; and AS3 (severe), ABI $<0.7$ or carotid plaque with stenosis $\geq 70 \%$.

\section{Statistical analysis}

Statistical analysis was performed using SPSS software, version 17.0 (Chicago, Ill, USA) and $R$ software [25]. Quantitative data are expressed as mean values \pm standard deviation, while qualitative variables are given in absolute and relative frequencies. Normal distribution was assessed by the Kolmogorov-Smirnoff test. $\mathrm{X}^{2}$ and Fisher exact's tests were used to compare categorical data, Student's t-test and Mann-Whitney's U-test for continuous data, ANOVA and Kruskal-Wallis's H-test for comparison of several groups and Pearson and Spearman's coefficients for numerical correlations. A significance level of 0.05 was accepted.

Table 1 Baseline demographic and clinical characteristics of the patients

\begin{tabular}{|c|c|c|c|c|c|c|c|}
\hline & $\begin{array}{l}\text { Controls } \\
n=559\end{array}$ & $\begin{array}{l}\text { CKD } \\
n=2445\end{array}$ & $\begin{array}{l}\text { CKD stage } 3 \\
n=937\end{array}$ & $\begin{array}{l}\text { CKD stages } 4-5 \\
n=820\end{array}$ & $\begin{array}{l}\text { CKD stage 5D } \\
n=688\end{array}$ & $\begin{array}{l}p \text { value } \\
\text { CKD vs controls }\end{array}$ & $\begin{array}{l}\mathrm{p} \text { value } \\
\text { Between CKD groups }\end{array}$ \\
\hline Male gender & $298(53.3)$ & $1509(61.7)$ & $621(66.3)$ & $478(58.3)$ & $409(59.4)$ & $<0.001$ & $<0.001$ \\
\hline Age (years) & $54.6 \pm 11.5$ & $57.9 \pm 12.8$ & $60.9 \pm 11.4$ & $58.7 \pm 12.3$ & $53.2 \pm 13.8$ & $<0.001$ & $<0.001$ \\
\hline \multicolumn{8}{|l|}{ Clinical history } \\
\hline Familial history of CVD & $62(11.1)$ & $213(8.7)$ & $93(9.9)$ & $73(8.9)$ & $47(6.8)$ & NS & NS \\
\hline Current smoker & $109(19.5)$ & $474(19.4)$ & $177(18.9)$ & $158(19.3)$ & $175(20.2)$ & NS & NS \\
\hline Former smoker & $228(40.8)$ & $862(35.3)$ & $343(36.6)$ & $279(34.0)$ & $204(34.9)$ & NS & NS \\
\hline Hypertension & $197(35.2)$ & $2183(89.3)$ & $827(88.3)$ & $766(93.4)$ & $590(85.8)$ & $<0.001$ & $<0.001$ \\
\hline Diabetes mellitus & $61(10.9)$ & $628(25.7)$ & $258(27.5)$ & $246(30.0)$ & $124(18.0)$ & $<0.001$ & $<0.001$ \\
\hline Dyslipidemia & $196(35.1)$ & $1587(64.9)$ & $657(70.1)$ & $567(69.1)$ & $363(52.8)$ & $<0.001$ & $<0.001$ \\
\hline CKD etiology & N/A & & & & & N/A & $<0.001$ \\
\hline Vascular & & $471(19.3)$ & $272(29.1)$ & $128(15.6)$ & $71(10.3)$ & & \\
\hline Glomerular & & $381(15.6)$ & $110(11.8)$ & $150(18.3)$ & $121(17.6)$ & & \\
\hline Diabetic & & $351(14.4)$ & $126(13.5)$ & $145(17.7)$ & $80(11.6)$ & & \\
\hline Tubulointerstitial & & $287(11.7)$ & $94(10.4)$ & $100(12.2)$ & $93(13.5)$ & & \\
\hline Cystic & & $239(9.8)$ & $58(6.2)$ & $85(10.4)$ & $96(14.0)$ & & \\
\hline Other & & $307(12.5)$ & 103 (10.6) & $102(12.4)$ & $102(14.8)$ & & \\
\hline Unknown & & $407(16.7)$ & 172 (18.4) & $110(13.4)$ & $125(18.2)$ & & \\
\hline
\end{tabular}




\section{Results}

Main clinical and demographical data are summarized in Table 1. Table 2 includes information related to anthropometrical data and pharmacological treatments at enrolment, while Table 3 aggregates results of laboratory values. Data are presented for total groups and for different CKD stages. There are remarkable differences in age, sex and prevalence and control of cardiovascular risk factors between CKD patients and controls, but also between different CKD stages. These differences will presumably have an effect on subclinical atheromatosis.

Results of tests to detect subclinical atheromatosis are showed in Table 4. There was no difference between controls and CKD patients, but cIMT was lower in patients with more advanced CKD (Figure 1). Statistically significant differences were shown when a model was used in which plaques in common carotid arteries were truncated to a cIMT value of $1.5 \mathrm{~mm}$.

On the contrary, CKD patients presented a higher prevalence of atheromatous plaques, both globally and in carotid and femoral arteries. No differences were found between CKD stages. It is important to highlight a high rate of patients with femoral but not carotid plaques (Figure 2).
Similar results were found with the measure of ABI: higher prevalence of pathologic values in CKD, with a progressive rise of prevalence in more advanced CKD. Besides, as CKD progresses, there are more patients with an $\mathrm{ABI}$ compatible with vascular stiffness $(\mathrm{ABI}>1.4)$ and lower with an $\mathrm{ABI}$ $<0.9$, compatible with distal ischemia (Figure 3).

Finally, AS was evaluated, with a higher rate of worse scores in CKD patients, but no significant differences between stages.

\section{Discussion}

NEFRONA is the first large cohort study evaluating the prevalence and evolution of subclinical atheromatosis in CKD patients, aimed to define the role of non-invasive early diagnostic tests.

Cardiovascular disease is the main cause of morbidity and mortality in CKD patients, and it continues to be so despite the better knowledge on vascular disease pathogenesis and the improvement in CKD treatments $[1,21,26]$. Appropriate evaluation of cardiovascular risk is essential, and several non-invasive and easily performable methods, like vascular ultrasound, are currently under study.

Table 2 Baseline anthropometrical data and treatments at enrolment

\begin{tabular}{|c|c|c|c|c|c|c|c|}
\hline & $\begin{array}{l}\text { Controls } \\
n=559\end{array}$ & $\begin{array}{l}\text { CKD } \\
n=2445\end{array}$ & $\begin{array}{l}\text { CKD stage } 3 \\
\mathrm{n}=937\end{array}$ & $\begin{array}{l}\text { CKD stages } 4-5 \\
n=820\end{array}$ & $\begin{array}{l}\text { CKD stage 5D } \\
n=688\end{array}$ & $\begin{array}{l}\text { p value } \\
\text { CKD vs controls }\end{array}$ & $\begin{array}{l}\text { p value } \\
\text { Between CKD } \\
\text { groups }\end{array}$ \\
\hline \multicolumn{8}{|l|}{ Anthropometrical data } \\
\hline SBP $(m m H g)$ & $133.2 \pm 17.7$ & $142.9 \pm 22.0$ & $142.9 \pm 20.2$ & $146.7 \pm 22.1$ & $138.4 \pm 23.4$ & $<0.001$ & $<0.001$ \\
\hline $\mathrm{DBP}(\mathrm{mmHg})$ & $80.0 \pm 9.7$ & $81.3 \pm 11.9$ & $81.6 \pm 10.2$ & $82.2 \pm 11.4$ & $80.0 \pm 14.2$ & 0.010 & 0.005 \\
\hline Pulse pressure (mmHg) & $53.2 \pm 13.0$ & $61.6 \pm 18.3$ & $61.3 \pm 16.9$ & $64.5 \pm 19.4$ & $58.4 \pm 18.3$ & $<0.001$ & $<0.001$ \\
\hline BMI $\left(\mathrm{Kg} / \mathrm{m}^{2}\right)$ & $28.1 \pm 4.5$ & $28.3 \pm 5.2$ & $29.2 \pm 4.9$ & $28.8 \pm 5.5$ & $26.5 \pm 4.9$ & NS & $<0.001$ \\
\hline Abdominal obesity (\%)* & 47.8 & 49.6 & 58.9 & 49.3 & $34.4^{\mathrm{a}}$ & NS & $<0.001$ \\
\hline \multicolumn{8}{|c|}{ Pharmacological treatments } \\
\hline Antihypertensive (\%) & 34.5 & 88.1 & 91.8 & 95.6 & 74.3 & $<0.001$ & $<0.001$ \\
\hline Hypolipidemic (\%) & 27.4 & 64.4 & 67.6 & 70.7 & 52.5 & $<0.001$ & $<0.001$ \\
\hline Antidiabetic (\%) & 9.5 & 21.9 & 23.5 & 25.2 & 15.8 & $<0.001$ & $<0.001$ \\
\hline Antiaggregation (\%) & 5.9 & 24.8 & 23.6 & 23.8 & 27.6 & $<0.001$ & NS \\
\hline Anticoagulation (\%) & 0.5 & 3.1 & 3.2 & 3.0 & 3.2 & $<0.001$ & NS \\
\hline Vitamin D (\%) & N/A & 38.7 & 18.0 & 50.4 & 53.1 & N/A & $<0.001$ \\
\hline Of which active (\%) & N/A & 32.1 & 12.0 & 42.8 & 46.9 & N/A & $<0.001$ \\
\hline Of wich native (\%) & N/A & 10.2 & 7.0 & 13.6 & 10.6 & N/A & $<0.001$ \\
\hline Phosphate binders (\%) & $\mathrm{N} / \mathrm{A}$ & 35.7 & 5.7 & 31.1 & 82.0 & $\mathrm{~N} / \mathrm{A}$ & $<0.001$ \\
\hline Non-calcium based (\%) & N/A & 22.2 & 1.0 & 14.7 & 60.1 & N/A & $<0.001$ \\
\hline Calcium based (\%) & $\mathrm{N} / \mathrm{A}$ & 21.1 & 4.9 & 20.4 & 43.8 & N/A & $<0.001$ \\
\hline ESA (\%) & $\mathrm{N} / \mathrm{A}$ & 35.6 & 5.7 & 32.2 & 80.4 & N/A & $<0.001$ \\
\hline Intravenous iron (\%) & $\mathrm{N} / \mathrm{A}$ & 18.7 & 1.7 & 8.2 & 54.5 & N/A & $<0.001$ \\
\hline
\end{tabular}

Data expressed as percentage or mean value \pm standard deviation. ${ }^{*}$ Abdominal obesity defined as waist circumference $>88 \mathrm{~cm}$ in women and $>102 \mathrm{~cm}$ in men. ${ }^{a}$ Waist circumference was not measured in peritoneal dialysis patients. Abbreviations: $C K D$ chronic kidney disease, $S B P$ systolic blood pressure, $D B P$ diastolic blood pressure, $B M I$ body mass index, ESA erythropoiesis stimulating agents, N/A not assessed, NS not significant. 
Table 3 Baseline laboratory values

\begin{tabular}{|c|c|c|c|c|c|c|c|}
\hline & $\begin{array}{l}\text { Controls } \\
n=559\end{array}$ & $\begin{array}{l}\text { CKD } \\
n=2445\end{array}$ & $\begin{array}{l}\text { CKD stage } 3 \\
n=937\end{array}$ & $\begin{array}{l}\text { CKD stages 4-5 } \\
n=820\end{array}$ & $\begin{array}{l}\text { CKD stage 5D } \\
n=688\end{array}$ & $\begin{array}{l}\text { p value } \\
\text { CKD vs controls }\end{array}$ & $\begin{array}{l}\text { p value } \\
\text { Between CKD } \\
\text { groups }\end{array}$ \\
\hline Creatinine $(\mathrm{mg} / \mathrm{dL})$ & $0.8 \pm 0.2$ & $4.1 \pm 3.3$ & $1.6 \pm 0.4$ & $3.3 \pm 1.3$ & $8.4 \pm 2.9$ & $<0.001$ & $<0.001$ \\
\hline $\operatorname{MDRD}\left(\mathrm{mL} / \mathrm{min} / 1.73 \mathrm{~m}^{2}\right)$ & $91.8 \pm 16.8$ & N/A & $43.5 \pm 8.7$ & $20.6 \pm 7.5$ & N/A & N/A & $\mathrm{N} / \mathrm{A}$ \\
\hline Urea $(\mathrm{mg} / \mathrm{dL})$ & $37.4 \pm 9.1$ & $101.6 \pm 48.1$ & $65.3 \pm 24.3$ & $121.9 \pm 47.5$ & $126.1 \pm 42.9$ & $<0.001$ & $<0.001$ \\
\hline Total cholesterol (mg/dL) & $203.4 \pm 35.6$ & $178.3 \pm 39.7$ & $187.4 \pm 36.5$ & $179.1 \pm 37.9$ & $164.9 \pm 42.4$ & $<0.001$ & $<0.001$ \\
\hline LDL-cholesterol (mg/dL) & $127.3 \pm 32.8$ & $101.8 \pm 33.7$ & $109.6 \pm 31.6$ & $101.9 \pm 32.7$ & $91.2 \pm 34.8$ & $<0.001$ & $<0.001$ \\
\hline HDL-cholesterol (mg/dL) & $53.9 \pm 15.4$ & $49.3 \pm 15.4$ & $50.9 \pm 15.4$ & $49.2 \pm 15.1$ & $47.3 \pm 15.6$ & $<0.001$ & $<0.001$ \\
\hline No-HDL-cholesterol (mg/dL) & $150.4 \pm 36.1$ & $129.3 \pm 37.4$ & $136.8 \pm 34.5$ & $130.6 \pm 36.3$ & $117.8 \pm 39.7$ & $<0.001$ & $<0.001$ \\
\hline Triglycerides (mg/dL) & $115.5 \pm 67.5$ & $145.0 \pm 82.3$ & $144.7 \pm 83.0$ & $149.8 \pm 85.7$ & $139.7 \pm 76.1$ & $<0.001$ & NS \\
\hline Glucose $(\mathrm{mg} / \mathrm{dL})$ & $101.4 \pm 23.6$ & $107.6 \pm 39.4$ & $110.8 \pm 37.4$ & $108.4 \pm 41.4$ & $102.3 \pm 39.2$ & NS & NS \\
\hline Hemoglobin (g/dL) & $14.5 \pm 1.4$ & $12.8 \pm 1.7$ & $13.8 \pm 1.7$ & $12.4 \pm 1.4$ & $11.9 \pm 1.4$ & $<0.001$ & $<0.001$ \\
\hline Transferrin (mg/dL) & $283.4 \pm 47.1$ & $220.1 \pm 48.8$ & $245.9 \pm 48.0$ & $220.7 \pm 42.2$ & $193.3 \pm 41.7$ & $<0.001$ & $<0.001$ \\
\hline TSAT (\%) & $24.9 \pm 12.4$ & $27.8 \pm 12.5$ & $25.8 \pm 10.5$ & $27.3 \pm 10.6$ & $30.4 \pm 15.5$ & 0.003 & $<0.001$ \\
\hline Ferritin $(\mathrm{ng} / \mathrm{mL})$ & $113.8 \pm 116.7$ & $244.2 \pm 308.8$ & $170.7 \pm 215.1$ & $190.2 \pm 167.7$ & $365.5 \pm 440.8$ & $<0.001$ & $<0.001$ \\
\hline Uric acid (mg/dL) & $5.1 \pm 1.4$ & $6.7 \pm 1.6$ & $6.8 \pm 1.6$ & $7.0 \pm 1.6$ & $6.1 \pm 1.3$ & $<0.001$ & $<0.001$ \\
\hline $\mathrm{hsCRP}(\mathrm{mg} / \mathrm{L})$ & $3.4 \pm 7.9$ & $4.7 \pm 9.3$ & $3.9 \pm 6.1$ & $4.8 \pm 9.9$ & $5.6 \pm 11.7$ & $<0.001$ & 0.020 \\
\hline Albumin (g/dL) & $4.4 \pm 0.3$ & $4.1 \pm 0.4$ & $4.2 \pm 0.4$ & $4.1 \pm 0.5$ & $3.9 \pm 0.5$ & $<0.001$ & $<0.001$ \\
\hline Corrected calcium (mg/dL) & $9.4 \pm 0.4^{\mathrm{a}}$ & $9.2 \pm 0.6$ & $9.5 \pm 0.5$ & $9.3 \pm 0.6$ & $9.1 \pm 0.7$ & $<0.001$ & $<0.001$ \\
\hline Phosphorus (mg/dL) & $3.5 \pm 0.5^{\mathrm{a}}$ & $4.1 \pm 1.1$ & $3.4 \pm 0.6$ & $4.1 \pm 0.8$ & $4.9 \pm 1.3$ & $<0.001$ & $<0.001$ \\
\hline Intact PTH $(\mathrm{pg} / \mathrm{mL})$ & N/A & $181.7 \pm 193.5$ & $85.6 \pm 69.0$ & $173.5 \pm 123.8$ & $297.1 \pm 273.2$ & N/A & $<0.001$ \\
\hline 25-hydroxi-vitamin D (ng/L) & $20.1 \pm 7.9$ & $16.1 \pm 7.5$ & $16.7 \pm 7.8$ & $16.2 \pm 6.8$ & $15.1 \pm 7.4$ & $<0.001$ & $<0.001$ \\
\hline 1,25-hydroxi-vitamin $\mathrm{D}(\mathrm{pg} / \mathrm{mL})$ & $33.6 \pm 13.9$ & $16.8 \pm 10.9$ & $21.5 \pm 11.2$ & $17.4 \pm 10.0$ & $8.3 \pm 5.1$ & $<0.001$ & $<0.001$ \\
\hline
\end{tabular}

Data expressed as mean value \pm standard deviation. ${ }^{2}$ Data available in $36 \%$ of subjects. Abbreviations: CKD chronic kidney disease, MDRD glomerular filtration rate estimated with the 4-variable MDRD equation, TSAT transferring saturation, PTH parathyroid hormone, hsCRP high-sensitivity C reactive protein, N/A not assessed, NS not significant.

In this population, we found that the CKD-group has a higher age and proportion of male subjects, and higher rates of hypertension, diabetes and dyslipidemia than the controls. However, this worse cardiovascular profile is more pronounced in earlier stages of CKD. The percentage of diabetic and vascular etiologies of CKD is proportionally lower in more advanced stages. Blood pressure values and BMI equally show this trend. These facts could be explained by an incidence-prevalence bias (or Neyman bias), since as renal dysfunction progresses, patients with worse cardiovascular health have a lower possibility of staying free of cardiovascular events, and hence, of being recruited for this study. There is probably a selection bias too, given that patients in CKD stage $5 \mathrm{~d}$ were significantly younger, and age has been shown the most important risk factor for atheromatosis development. It is also rather remarkable the high rate of well-known cardiovascular risk factors in stage 3 CKD patients. Altogether, it seems increasingly important and evidence-based that primary prevention strategies must be started earlier in the course of the disease.
All evaluated pharmacological treatments are much more frequently prescribed in CKD patients than in controls, as it was expected. Antihypertensive, antidiabetic and hypolipidemic drugs are more common in CKD stages 4-5 than in stage 3, but in dialysis these treatments are much less frequent. This tendency is explained by the baseline differences, but also by the well-known reverse epidemiology effect in cardiovascular risk factors: dialysis patients usually have lower LDL-cholesterol levels, so they are prescribed less statins.

On the other side, treatments for control of anemia and mineral-bone disorders grow exponentially in more advanced CKD stages. Two interesting pieces of information can be highlighted: first, a very low percentage of patients treated with native vitamin $\mathrm{D}$ regardless of the stage, despite the usually low plasma levels and the growing evidence of the benefits of vitamin D supplementation [27-30]; second, the high rate of patients in more advanced stages of CKD receiving calcium-based phosphate binders, despite their extremely high risk of vascular calcification. 
Table 4 Subclinical atheromatosis detection in CKD and non-CKD patients

\begin{tabular}{|c|c|c|c|c|c|c|c|}
\hline & $\begin{array}{l}\text { Controls } \\
n=559\end{array}$ & $\begin{array}{l}\text { CKD } \\
n=2445\end{array}$ & $\begin{array}{l}\text { CKD stage } 3 \\
n=937\end{array}$ & $\begin{array}{l}\text { CKD stages } 4-5 \\
n=820\end{array}$ & $\begin{array}{l}\text { CKD stage 5D } \\
n=688\end{array}$ & $\begin{array}{l}\text { p value } \\
\text { CKD vs } \\
\text { controls }\end{array}$ & $\begin{array}{l}\text { p value } \\
\text { Between CKD } \\
\text { groups }\end{array}$ \\
\hline \multicolumn{8}{|l|}{ cIMT (mm) } \\
\hline All patients ${ }^{a}$ & $0.705(0.605-0.815)$ & $0.725(0.615-0.870)$ & $0.765(0.645-0.891)$ & $0.705(0.600-0.855)$ & $0.695(0.595-0.850)$ & $<0.001$ & $<0.001$ \\
\hline Plaque-free common carotid ${ }^{b}$ & $0.710 \pm 0.150$ & $0.710 \pm 0.160$ & $0.749 \pm 0.164$ & $0.699 \pm 0.157$ & $0.689 \pm 0.154$ & NS & $<0.001$ \\
\hline \multicolumn{8}{|l|}{$\begin{array}{l}\text { Atheroma plaque } \\
\text { presence (\%) }\end{array}$} \\
\hline Any territory & 52.4 & 70.0 & 70.5 & 69.6 & 70.0 & $<0.001$ & NS \\
\hline Only carotid artery & 18.1 & 18.8 & 19.3 & 17.6 & 19.4 & $<0.001$ & NS \\
\hline Only femoral artery & 10.0 & 12.6 & 12.9 & 13.3 & 11.2 & $<0.001$ & NS \\
\hline Carotid and femoral arteries & 24.3 & 38.7 & 38.3 & 38.6 & 39.3 & $<0.001$ & NS \\
\hline \multicolumn{8}{|l|}{$A B I$} \\
\hline Mean $A B \mid$ & $1.03 \pm 0.10$ & $1.06 \pm 0.27$ & $1.02 \pm 0.19$ & $1.05 \pm 0.21$ & $1.14 \pm 0.38$ & NS & $<0.001$ \\
\hline Pathologic ABI (\%) & 12.3 & 28.0 & 25.3 & 27.1 & 32.9 & $<0.001$ & 0.003 \\
\hline$A B \mid>1.4(\%)$ & 1.4 & 11.0 & 5.6 & 10.2 & 19.5 & $<0.001$ & $<0.001$ \\
\hline$A B \mid<0.9(\%)$ & 10.9 & 17.0 & 19.8 & 16.9 & 13.4 & $<0.001$ & 0.003 \\
\hline Atheromatosis score (\%) & & & & & & $<0.001$ & NS \\
\hline AS 0 & 38.1 & 30.3 & 28.4 & 33.4 & 29.3 & & \\
\hline AS 1 & 20.0 & 11.5 & 13.1 & 9.9 & 11.0 & & \\
\hline AS 2 & 41.7 & 53.5 & 54.1 & 51.5 & 55.2 & & \\
\hline AS 3 & 0.0 & 4.4 & 4.2 & 5.0 & 4.1 & & \\
\hline
\end{tabular}

Data expressed as percentage or mean value \pm standard deviation. ${ }^{a}$ Values for all the patients, truncating IMT values of patients with plaques at 1.5 mm. Data expressed as median (interquartile interval). ${ }^{b}$ Values for patients with no plaque in any common carotid artery. Abbreviations: CKD chronic kidney disease, cIMT common carotid intima-media thickness, $A B I$ ankle-brachial index, $A S$ atheromatosis score, NS not significant.

In the evaluation of laboratory information, mean values show that patients are globally well controlled, and we confirm the reverse epidemiology phenomenon in lipids (the frequently described tendency to spontaneously normalize their lipid profile in end-stage renal disease, that has been associated to more inflammation and malnutrition). It is important to highlight the low values of inflammation markers in all CKD stages. Anemia and mineral-bone disorder parameter analysis appear to show a mainly good adherence to current guidelines, at least in this subpopulation free of cardiovascular history.

cIMT is a good cardiovascular risk marker in subjects with normal renal function [31,32]. A few studies have also proved that cIMT can predict ischemic events in CKD patients, but most of them were conducted in dialysis patients with small sample sizes [33-37]. In the NEFRONA study, we did not find any difference in cIMT between CKD patients and controls, unless plaque presence was corrected to a higher cIMT value. However, we did find that cIMT was higher in CKD stage 3, and progressively lower with more advanced stages. Again, there seems to be a survival bias involved, given the cross-sectional nature of this data, and an incidence-prevalence bias, since only patients free of prior cardiovascular events were included. It is likely that patients with more advanced CKD have a lower cIMT because those who would have had a higher cIMT probably already had a cardiovascular event. It is a well-known factor that CKD patients have a higher chance of suffering a fatal or non-fatal vascular event than eventually requiring dialysis, so those patients arriving to more advance CKD stages are usually considered "cardiovascular survivors" [21]. This fact should be proved in the prospective analysis of the NEFRONA study. More specific data about cIMT, such as different site measures or differences between left and right cIMT, is under current analysis.

Atheromatous plaque presence directly affects cardiovascular prognosis in general population [38], and it seems clearly involved in CKD morbimortality [39]. There is evidence showing the predictive effect of the presence and extent of vascular plaques on dialysis patients $[40,41]$. Besides, the place where calcium is deposited is also important: it seems that intimal rather than medial calcification has a worse prognosis [42-44]. In our study, plaque prevalence is significantly higher in CKD patients than in subjects with normal renal function, but there is no difference between CKD stages. We explain this fact by the same biases as for cIMT; age seems to be the main determinant for the atheromatous 


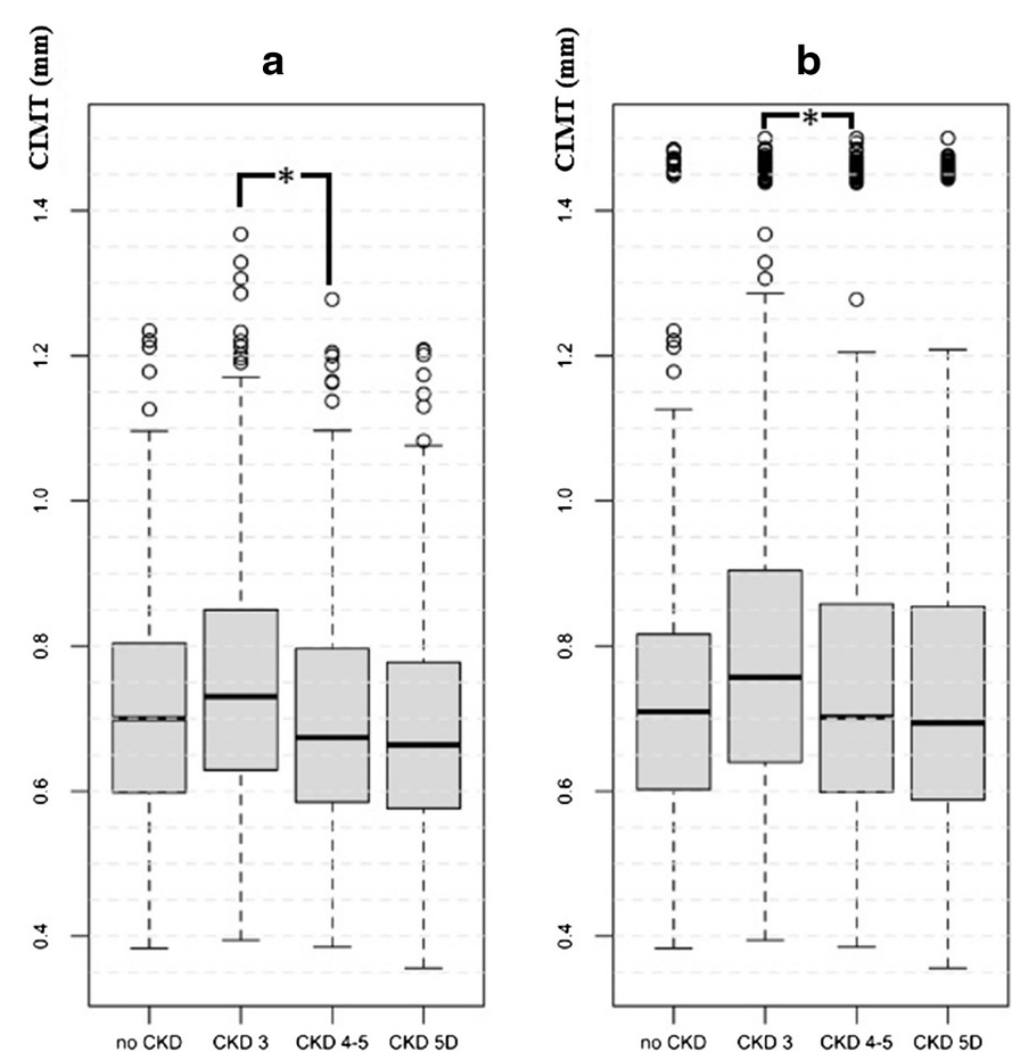

Figure 1 Mean carotid intima-media thickness in controls and chronic kidney disease patients. Distribution of carotid intima-media thickness (CIMT) in controls and in different chronic kidney disease (CKD) stages. a) Patients without plaques in common carotid arteries. b) All patients (plaques truncated at $1.5 \mathrm{~mm}$ ). ${ }^{*} \mathrm{p}<0.001$.

load, so only younger patients with less risk factors reach stage 5 CKD free of cardiovascular events.

One interesting finding is the high rate of femoral plaques, even in patients with no carotid atheromatosis (between 10 and 12\%). Some studies have started to explore the evaluation of ultrasound diagnosis of femoral

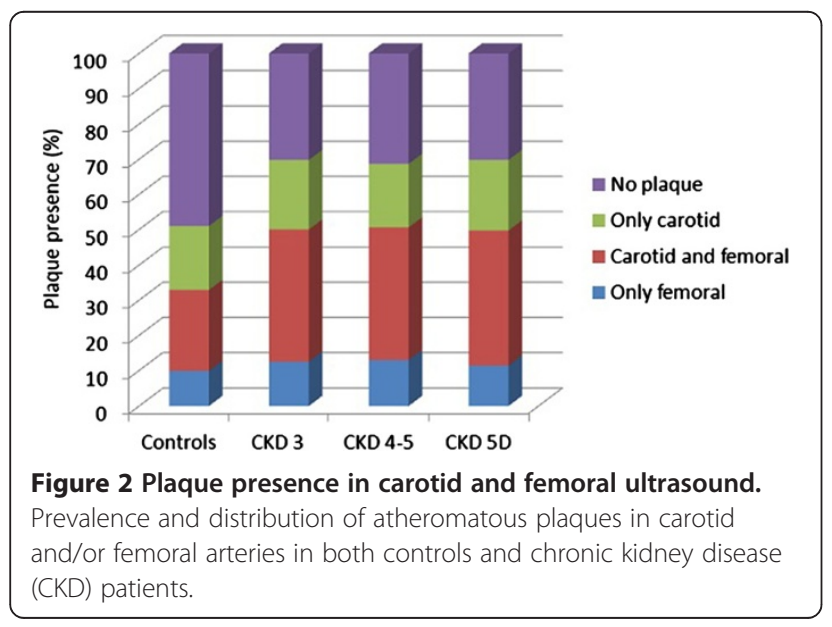

plaques in general population and in other pathologies [45,46]. In CKD, evaluation of this site has been studied by simple radiology, and it has been associated to peripheral artery disease and cardiovascular prognosis [47]. In order to perform an adequate vascular risk assessment, femoral ultrasound should complement carotid ultrasound. More extensive data on the specific characteristics

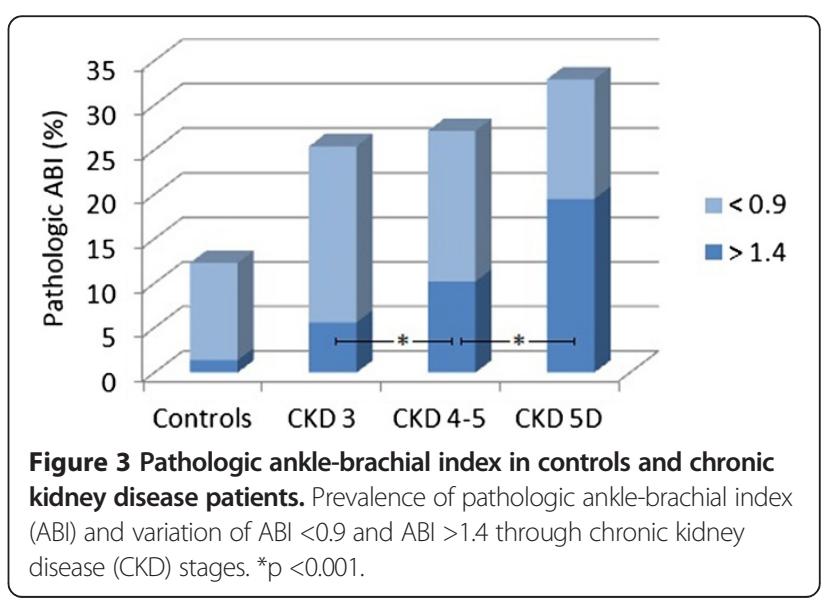


of atheromatous plaques and difference between subgroups is beyond the aim of this article, and it has partially been published [48].

Peripheral artery disease, defined as a pathologic ankle-brachial index has also shown to have a predictive value over new-onset cardiovascular events in non-CKD [49,50] and CKD subjects [51-53], but again, most data come from dialysis cohorts. In the NEFRONA study, CKD was associated with a pathologic ABI. In more advanced stages of CKD, pathologic ABI was more frequently in the higher rank ( $>1.4$, related to severe vascular calcification) than in the ischemic range $(<0.9)$.

Altogether, CKD patients present a higher atheromatous score than non-CKD subjects, but no difference could be found between CKD stages, probably due to the cross-sectional nature of this initial analysis and the uneven distribution of cardiovascular risk factors. Further and more complete information will be revealed when follow-up data are published.

This study has some limitations, being the first one the cross-sectional nature of these initial results. There is an intentional bias, because only patients with no history of cardiovascular events were included. This bias was necessary, but its consequences have to be considered when interpreting the results. Finally, control subjects are not perfectly matched, and also present a selection bias: they were selected from patients seeking medical attention in Primary Care centers, so they might not be a fully representative sample of the general population.

\section{Conclusions}

NEFRONA is the first study presenting the real prevalence of subclinical atheromatosis in a large cohort of CKD patients, compared to subjects with normal renal function. As an added value, all diagnostic tests were performed by the same exploration teams, avoiding differences between observers.

The cardiovascular risk profiles and treatment policies through different CKD stages is also presented. Our results indirectly suggest that patients with more advanced renal dysfunction are those who have avoided cardiovascular events.

Subclinical atheromatosis is very prevalent in chronic kidney disease patients. Femoral atheromatous plaques are very frequent, even in patients without carotid plaques; hence, femoral ultrasound should also be performed for a correct evaluation of cardiovascular risk. Further data on the evolution and prognosis of subclinical atheromatosis will contribute to the understanding of atheromatous disease in kidney disease when the prospective analysis of the NEFRONA study is published. This initial analysis should generate new hypothesis and stimulate the study of the effect of earlier primary prevention strategies on cardiovascular morbidity in CKD patients.

\section{Competing interests}

The authors declare that they have no competing interests.

\section{Authors' contributions}

EF, JV: Principal Investigators, conception and design of the study. DA: writing of the manuscript. DA, AB, MMA, JV, TV, EF: design and coordination, manuscript draft, critical review and final approval of the manuscript. EF, JV: study funding.

\section{Authors' information}

Jose Manuel Valdivielso and Elvira Fernández share senior authorship.

\section{Acknowledgements}

The authors would like to thank the NEFRONA team (Eva Castro, Virtudes María, Teresa Molí, Meritxell Soria) and the Biobank of RedlnRen for their invaluable support. The NEFRONA study is funded by a research grant from AbbVie and the Spanish government RETIC (RD12/0021) and FIS PS10/00946. The NEFRONA study investigator group is composed by the following: Aladrén Regidor, Ma José. Hospital Comarcal Ernest Lluch (Calatayud); Almirall, Jaume; Ponz, Esther. Corporació Parc Taulí (Barcelona); Arteaga Coloma, Jesús. Hospital de Navarra (Pamplona); Bajo Rubio, Ma Auxiliadora, Hospital La Paz (Madrid); Belart Rodríguez, Montserrat. Sistemes Renals (Lleida); Bielsa-García. Sara, Hospital Obispo Polanco (Teruel); Bover Sanjuan, Jordi. Fundació Puigvert. IIB Sant Pau (Barcelona); Bronsoms Artero, Josep. Clínica Girona (Girona); Cabezuelo Romero, Juan B; Muray Cases, Salomé. Hospital Reina Sofía (Murcia); Calviño Varela, Jesús. Hospital Universitario Lugus Augusti (Lugo); Caro Acevedo, Pilar. Clínica Ruber (Madrid); Carreras Bassa, Jordi. Diaverum Baix Llobregat (Barcelona); Cases Amenós, Aleix; Massó Jiménez, Elisabet. Hospital Clínic (Barcelona); Castilla Pérez, Jesús. Hospital de la Defensa (Zaragoza); Cigarrán Guldris, Secundino; López Prieto, Saray. Hospital Da Costa (Lugo); Comas Mongay, Lourdes. Hospital General de Vic (Barcelona); Comerma, Isabel. Hospital General de Manresa (Barcelona); Compte Jové, Ma Teresa, Hospital Santa Creu Jesús (Tarragona); Cuberes Izquierdo, Marta. Hospital Reina Sofía (Navarra); de Álvaro, Fernando; Hevia Ojanguren, Covadonga. Hospital Infanta Sofía (Madrid); de Arriba de la Fuente, Gabriel. Hospital Universitario Guadalajara (Guadalajara); del Pino y Pino, Ma Dolores. Complejo Hospitalario Universitario Torrecardenas (Almería); Diaz-Tejeiro Izquierdo, Rafael. Hospital Virgen de la Salud (Toledo); Dotori, Marta. USP Marbella (Málaga); Duarte, Verónica. Hospital de Terrassa (Barcelona); Estupiñan Torres, Sara. Hospital Universitario Canarias (Santa Cruz de Tenerife); Fernández Reyes, Ma José. Hospital de Segovia (Segovia); Fernández Rodríguez, Ma Loreto. Hospital Príncipe de Asturias (Madrid); Fernández, Guillermina. Clínica Santa Isabel (Sevilla); Galán Serrano, Antonio. Hospital General Universitario de Valencia (Valencia); García Cantón, Cesar. Hospital Universitario Insular de Gran Canaria (Las Palmas); García Herrera, Antonio L. Hospital Universitario Puerto Real (Cádiz); García Mena, Mercedes. Hospital San Juan de Dios (Zaragoza); Gil Sacaluga, Luis; Aguilar, Maria. Hospital Virgen del Rocío (Sevilla); Górriz, José Luis. Hospital Universitario Doctor Peset (Valencia); Huarte Loza, Emma. Hospital San Pedro (Logroño); Lerma, José Luis. Hospital Universitario Salamanca (Salamanca); Liebana Cañada, Antonio. Hospital de Jaén (Jaén); Marín Álvarez, Jesús Pedro. Hospital San Pedro de Alcántara (Cáceres); Martín Alemany, Nàdia. Hospital Josep Trueta (Girona); Martín García, Jesús. Hospital Nuestra Señora de Sonsoles (Ávila); Martínez Castelao, Alberto. Hospital Universitari de Bellvitge (Barcelona); Martínez Villaescusa, María. Complejo Hospitalario Universitario de Albacete (Albacete); Martínez, Isabel. Hospital Galdakao (Bilbao); Moina Eguren, Iñigo. Hospital Basurto (Bilbao); Moreno Los Huertos, Silvia. Hospital Santa Bárbara (Soria); Mouzo Mirco, Ricardo. Hospital El Bierzo, Ponferrada (León); Munar Vila, Antonia. Hospital Universitari Son Espases (Palma de Mallorca); Muñoz Díaz, Ana Beatriz. Hospital Virgen del Consuelo (Valencia); Navarro González, Juan F. Hospital Universitario Nuestra Señora de Candelaria (Santa Cruz de Tenerife); Nieto, Javier; Carreño, Agustín. Hospital General Universitario de Ciudad Real (Ciudad Real); Novoa Fernández, Enrique. Complexo Hospitalario de Ourense (Ourense); Ortiz, Alberto; Fernandez, Beatriz. IIS-Fundación Jiménez Díaz (Madrid); Paraíso, Vicente. Hospital Universitario del Henares (Madrid); Pérez Fontán, Miguel. Complejo Hospitalario Universitario A Coruña (A Coruña); Peris Domingo, Ana. Hospital Francesc de Borja (Valencia); Piñera Haces, Celestino. Hospital Universitario Marqués de Valdecilla (Santander); Prados Garrido, Ma Dolores. Hospital Universitario San Cecilio (Granada); Prieto Velasco, Mario. Hospital de León (León); Puig Marí, Carmina. Hospital d'Igualada (Barcelona); Rivera Gorrín, Maite. Hospital Universitario Ramón y Cajal (Madrid); Rubio, Esther. Hospital Puerta del Hierro (Madrid); Ruiz, Pilar. Hospital Sant Joan Despí Moisès Broggi (Barcelona); 
Salgueira Lazo, Mercedes; Martínez Puerto, Ana Isabel. Hospital Virgen Macarena (Sevilla); Sánchez Tomero, José Antonio. Hospital Universitario de la Princesa (Madrid); Sánchez, José Emilio. Hospital Universitario Central de Asturias (Oviedo); Sans Lorman, Ramon. Hospital de Figueres (Girona); Saracho, Ramon. Hospital de Santiago (Vitoria); Sarrias, Maria; Prat, Oreto. Hospital Universitari Vall d'Hebron (Barcelona); Soler, María José; Barrios, Clara. Hospital del Mar (Barcelona); Sousa, Fernando. Hospital Rio Carrión (Palencia); Toran, Daniel. Hospital General de Jerez (Cadiz); Tornero Molina, Fernando. Hospital de Sureste (Arganda del Rey); Usón Carrasco, José Javier. Hospital Virgen de la Luz (Cuenca); Valera Cortes, Ildefonso. Hospital Virgen de la Victoria (Málaga); Vilaprinyo del Perugia, Ma Merce. Institut Catala d'Urologia i Nefrologia (Barcelona); Virto Ruiz, Rafael C. Hospital San Jorge (Huesca).

\section{Author details}

Nephrology Department, Hospital Universitari Arnau de Vilanova, Avda. Rovira Roure 80, 25198 Lleida, Spain. ${ }^{2}$ Unit for Detection and Treatment of Atherotrombotic Disease (UDETMA), Nephrology Department, Hospital Universitari Arnau de Vilanova, Avda. Rovira Roure 80, 25198 Lleida, Spain. ${ }^{3}$ Statistics Department, IRB-Lleida, Hospital Universitari Arnau de Vilanova, Avda. Rovira Roure 80, 25198 Lleida, Spain. ${ }^{4}$ Experimental Nephrology Laboratory, IRB-Lleida, Hospital Universitari Arnau de Vilanova, Avda. Rovira Roure 80, 25198 Lleida, Spain. ${ }^{5}$ Spanish Renal Investigation Network RedInRen, Instituto de Salud Carlos III, Madrid, Spain.

Received: 2 June 2014 Accepted: 2 October 2014

Published: 18 October 2014

\section{References}

1. U.S. Renal Data System: USRDS 2013 Annual Data Report: Atlas of Chronic Kidney Disease and End-Stage Renal Disease in the United States. In . Bethesda, MD: National Institutes of Health, National Institute of Diabetes and Digestive and Kidney Diseases; 2013.

2. Sarnak MJ, Levey AS, Schoolwerth AC, Coresh J, Culleton B, Hamm LL, McCullough PA, Kasiske BL, Kelepouris E, Klag MJ, Parfrey P, Pfeffer M, Raij L, Spinosa DJ, Wilson PW: Kidney disease as a risk factor for development of cardiovascular disease: a statement from the American heart association councils on kidney in cardiovascular disease, high blood pressure research, clinical cardiology, and epidemiology and prevention. Circulation 2003, 108:2154-2169.

3. Stenvinkel P, Carrero JJ, Axelsson J, Lindholm B, Heimbürger O, Massy Z: Emerging biomarkers for evaluating cardiovascular risk in the chronic kidney disease patient: how do new pieces fit into the uremic puzzle? Clin J Am Soc Nephrol 2008, 3:505-521.

4. Rubin C, Nolin TD, Himmelfarb J: Are biomarkers useful for assessing cardiovascular risk in patients with chronic kidney disease? Curr Opin Nephrol 2007, 16:506-511.

5. Valdivielso JM, Coll B, Martín-Ventura JL, Moreno JA, Egido J, Fernández E, Blanco-Colio LM: Soluble TWEAK is associated with atherosclerotic burden in patients with chronic kidney disease. J Nephrol 2013, 26:1105-1113

6. Coll B, Rodríguez JA, Craver L, Orbe J, Martínez-Alonso M, Ortiz A, Díez J, Beloqui O, Borras M, Valdivielso JM, Fernández E, Páramo JA: Serum levels of matrix metalloproteinase- 10 are associated with the severity of atherosclerosis in patients with chronic kidney disease. Kidney Int 2010, 78:1275-1280

7. Franczyk-Skóra B, Gluba A, Banach M, Kozłowski D, Małyszko J, Rysz J: Prevention of sudden cardiac death in patients with chronic kidney disease. BMC Nephrol 2012, 13:162.

8. Whitman IR, Feldman HI, Deo R: CKD and sudden cardiac death: epidemiology, mechanisms, and therapeutic approaches. J Am Soc Nephrol 2012, 23:1929-1939.

9. Shamseddin MK, Parfrey PS: Sudden cardiac death in chronic kidney disease: epidemiology and prevention. Nat Rev Nephrol 2011, 7:145-154.

10. Keane WF, Tomassini JE, Neff DR: Lipid abnormalities in patients with chronic kidney disease: implications for the pathophysiology of atherosclerosis. J Atheroscler Thromb 2013, 20:123-133.

11. Coll B, Betriu A, Martinez-Alonso M, Borras M, Craver L, Amoedo ML, Marco MP, Sarro F, Junyent M, Valdivieso JM, Fernandez E: Cardiovascular risk factors underestimate atherosclerotic burden in chronic kidney disease: usefulness of non-invasive tests in cardiovascular assessment. Nephrol Dial Transplant 2010, 25:3017-3025.
12. Shoji T, Maekawa K, Emoto M, Okuno S, Yamakawa T, Ishimura E, Inaba M, Nishizawa Y: Arterial stiffness predicts cardiovascular death independent of arterial thickness in a cohort of hemodialysis patients. Atherosclerosis 2010, 210:145-149.

13. Hojs R, Bevc S, Ekart R: Biomarkers in hemodialysis patients. Adv Clin Chem 2012, 57:29-56

14. Wang AY, Wai-Kei Lam C: The diagnostic utility of cardiac biomarkers in dialysis patients. Semin Dial 2012, 25:388-396.

15. Naghavi M, Falk E, Hecht HS, Shah PK, for the SHAPE Task Force: The first SHAPE (Screening for Heart Attack Prevention and Education) guideline. Crit Pathw Cardiol 2006, 5:187-190.

16. Coll B, Betriu A, Feinstein SB, Valdivielso JM, Zamorano JL, Fernández E: The role of carotid ultrasound in assessing carotid atherosclerosis in individuals at low-to-intermediate cardiovascular risk. Rev Esp Cardiol 2013, 66:929-934.

17. Salk I, Yildiz G, Egilmez H, Atalar MH, Candan F, Cetin A: Carotid artery Doppler ultrasonography in patients with chronic kidney disease. Med Sci Monit 2014, 20:11-17.

18. Junyent M, Martinez M, Borras M, Coll B, Valdivieso JM, Vidal T, Sarro F, Roig J, Craver L, Fernandez E: Predicting cardiovascular disease morbidity and mortality in chronic kidney disease in Spain. The rationale and design of NEFRONA: a prospective, multicenter, observational cohort study. BMC Nephrol 2010, 11:14

19. Junyent M, Martínez M, Borrás M, Bertriu A, Coll B, Craver L, Marco MP, Sarró F, Valdivielso JM, Fernández E: Usefulness of imaging techniques and novel biomarkers in the prediction of cardiovascular risk in patients with chronic kidney disease in Spain: the NEFRONA project. Nefrologia 2010, 30:119-126.

20. Levey AS, Bosch JP, Lewis JB, Greene T, Rogers N, Roth D: A more accurate method to estimate glomerular filtration rate from serum creatinine: a new prediction equation. Modification of diet in renal disease study group. Ann Intern Med 1999, 130:461-470.

21. Go AS, Chertow GM, Fan D, McCulloch CE, Hsu C: Chronic kidney disease and the risks of death, cardiovascular events, and hospitalization. $N$ Engl J Med 2004, 351:1296-1305.

22. Stein JH, Korcarz CE, Hurst RT, Lonn E, Kendall CB, Mohler ER, Najjar SS Rembold CM, Post WS, American Society of Echocardiography Carotid Intima-Media Thickness Task Force: Use of carotid ultrasound to identify subclinical vascular disease and evaluate cardiovascular disease risk: a consensus statement from the American society of echocardiography carotid intima-media thickness task force. Endorsed by the society for vascular medicine. J Am Soc Echocardiogr 2008, 21:93-111.

23. Schröder F, Diehm N, Kareem S, Ames M, Pira A, Zwettler U, Lawall H, Diehm C: A modified calculation of ankle-brachial pressure index is far more sensitive in the detection of peripheral arterial disease. J Vasc Surg 2006, 44:531-536.

24. Nead KT, Cooke JP, Olin JW, Leeper NJ: Alternative ankle-brachial index method identifies additional at-risk individuals. J Am Coll Cardiol 2013, 62:553-559.

25. R Core Team: A Language and Environment for Statistical Computing. $R$ Foundation for Statistical Computing, Vienna, Austria.. http://www.R-project.org/.

26. Foley RN, Parfrey PS, Sarnak MJ: Epidemiology of cardiovascular disease in chronic renal disease. J Am Soc Nephrol 1998, 9(Suppl 12):16-23.

27. Li YC: Vitamin D in chronic kidney disease. Contrib Nephrol 2013, 180:98-109.

28. Melamed ML, Thadhani RI: Vitamin D therapy in chronic kidney disease and end stage renal disease. Clin J Am Soc Nephrol 2012, 7:358-365.

29. Vaidya A, Forman JP: Vitamin D and vascular disease: the current and future status of vitamin $D$ therapy in hypertension and kidney disease. Curr Hypertens Rep 2012, 14:111-119.

30. Singer RF: Vitamin $D$ in dialysis: defining deficiency and rationale for supplementation. Semin Dial 2013, 26:40-46.

31. Riley WA: Cardiovascular risk assessment in individual patients from carotid intimal-medial thickness measurements. Curr Atheroscler Rep 2004, 6:225-231.

32. Lorenz MW, Markus HS, Bots ML, Rosvall M, Sitzer M: Prediction of clinical cardiovascular events with carotid intima-media thickness: a systematic review and meta-analysis. Circulation 2007, 115:459-467.

33. Benedetto FA, Mallamaci F, Tripepi G, Zoccali C: Prognostic value of ultrasonographic measurement of carotid intima media thickness in dialysis patients. J Am Soc Nephrol 2001, 12:2458-2464. 
34. Ekart R, Hojs R, Hojs-Fabjan T, Balon BP: Predictive value of carotid intima media thickness in hemodialysis patients. Artif Organs 2005, 29:615-619.

35. Nishizawa Y, Shoji T, Maekasa K, Nagasue K, Okuno S, Kim M, Emoto M, Ishimura E, Nakatani T, Miki T, Inaba M: Intima-media thickness of carotid artery predicts cardiovascular mortality in hemodialysis patients. Am J Kidney Dis 2003, 41(Suppl 1):76-79.

36. Kato A, Takita T, Maruyama Y, Kumagai H, Hishida A: Impact of carotid atherosclerosis on long-term mortality in chronic hemodialysis patients. Kidney Int 2003, 64:1472-1479.

37. Szeto C, Chow K, Woo K, Chook P, Ching-Ha B, Leung C, Kam-Tao P: Carotid intima media thickness predicts cardiovascular diseases in Chinese predialysis patients with chronic kidney disease. J Am Soc Nephrol 2007, 18:1966-1972.

38. Rennenberg RJ, Kessels AG, Schrgers $L$, van Engelshoven JM, de Leeuw PW Kroon AA: Vascular calcifications as a marker of increased cardiovascular risk: a meta-analysis. Vasc Health Risk Manag 2009, 5:185-197.

39. Disthabanchong S: Vascular calcification in chronic kidney disease: Pathogenesis and clinical implication. World J Nephrol 2012, 1:43-53.

40. Mizobuchi M, Towler D, Slatopolsky E: Vascular calcification: the killer of patients with chronic kidney disease. J Am Soc Nephrol 2009, 20:1453-1464

41. Blacher J, Guerin AP, Pannier B, Marchais SJ, London GM: Arterial calcifications, arterial stiffness, and cardiovascular risk in end-stage renal disease. Hypertension 2001, 38:938-942.

42. London G, Guérin A, Marchais S, Métivier F, Pannier B, Adda H: Arterial media calcification in end-stage renal disease: impact on all-cause and cardiovascular mortality. Nephrol Dial Transplant 2003, 18:1731-1740.

43. Maeda S, Sawayama Y, Furusyo N, Shigematsu M, Hayashi J: The association between fatal vascular events and risk factors for carotid atherosclerosis in patients on maintenance hemodialysis: plaque number of dialytic atherosclerosis study. Atherosclerosis 2009, 204:549-555.

44. Coll B, Betriu A, Martínez-Alonso M, Amoedo ML, Arcidiacono MV, Borras M, Valdivielso JM, Fernández E: Large artery calcification on dialysis patients is located in the intima and related to atherosclerosis. Clin J Am Soc Nephrol 2011, 6:303-310.

45. Panayiotou AG, Griffin M, Kouis P, Tyllis T, Georgiou N, Bond D, Nicolaides AN: Association between presence of the metabolic syndrome and its components with carotid intima-media thickness and carotid and femoral plaque area: a population study. Diabetol Metab Syndr 2013, 5:44.

46. Frerix M, Stegbauer J, Kreuter A, Weiner SM: Atherosclerotic plaques occur in absence of intima-media thickening in both systemic sclerosis and systemic lupus erythematosus: a duplexsonography study of carotid and femoral arteries and follow-up for cardiovascular events. Arthritis Res Ther 2014, 16:R54.

47. Adragao T, Pires A, Branco P, Castro R, Oliveira A, Nogueira C, Bordalo J, Curto JD, Prata MM: Ankle-brachial index, vascular calcifications and mortality in dialysis patients. Nephrol Dial Transplant 2012, 27:318-325.

48. Betriu A, Martinez-Alonso M, Arcidiacono MV, Cannata-Andia J, Pascual J, Valdivielso JM, Fernández E, on Behalf of the Investigators From the NEFRONA Study: Prevalence of subclinical atheromatosis and associated risk factors in chronic kidney disease: the NEFRONA study. Nephrol Dial Transplant. in press.

49. Criqui MH, Langer RD, Fronek A, Feigelson HS, Klauber MR, MCCann TJ, Browner A: Mortality over a period of 10 years in patients with peripheral arterial disease. N Engl J Med 1992, 326:381-386.

50. Ankle Brachial Index Collaboration, Fowkes FG, Murray GD, Butcher I, Heald CL, Lee RJ, Chambless LE, Folsom AR, Hirsch AT, Dramaix M, de Backer G, Wautrecht JC, Kornitzer M, Newman AB, Cushman M, Sutton-Tyrrell K, Fowkes FG, Lee AJ, Price JF, D'Agostino RB, Murabito JM, Norman PE, Jamrozik K, Curb JD, Masaki KH, Rodríquez BL, Dekker JM, Bouter LM, Heine RJ, Nijpels G, et al: Ankle brachial index combined with Framingham Risk Score to predict cardiovascular events and mortality: a meta-analysis. JAMA 2008, 300:197-208.

51. Ono K, Tsuchida A, Kawai H, Matsuo H, Wakamatsu R, Maezawa A, Yano S, Kawada T, Nojima Y: Ankle-brachial blood pressure index predicts all-cause and cardiovascular mortality in hemodialysis patients. J Am Soc Nephrol 2003, 14:1591-1598.
52. Liu JH, Lin HH, Yang YF, Liu YL, Kuo HL, Wang IK, Chou CY, Huang CC: Subclinical peripheral artery disease in patients undergoing peritoneal dialysis: risk factors and outcome. Perit Dial Int 2009, 29:64-71.

53. Jimenez ZN, Pereira BJ, Romão JE Jr, Makida SC, Abensur H, Moyses RM, Elias RM: Ankle-brachial index: a simple way to predict mortality among patients on hemodialysis-a prospective study. PLoS One 2012, 7:e42290

doi:10.1186/1471-2369-15-168

Cite this article as: Arroyo et al:: Observational multicenter study to evaluate the prevalence and prognosis of subclinical atheromatosis in a Spanish chronic kidney disease cohort: baseline data from the NEFRONA study. BMC Nephrology 2014 15:168.

\section{Submit your next manuscript to BioMed Central and take full advantage of:}

- Convenient online submission

- Thorough peer review

- No space constraints or color figure charges

- Immediate publication on acceptance

- Inclusion in PubMed, CAS, Scopus and Google Scholar

- Research which is freely available for redistribution 